\section{寺田一郎·岩元純治郎·三宅晴久}

\title{
Polymeric Membrane for Dehumidification and Air Dryer System
}

\author{
Ichiro Terada, Junjiro Iwamoto and Haruhisa Miyake \\ Research Center, Asahi Glass Co., Ltd. \\ 1150 Hazawa-cho, Kanagawa-ku, Yokohama 221, Japan
}

\begin{abstract}
Water vapor permeation properties of fluorinated ion exchange polymer membranes were evaluated. Functional group in side chain end, measurement temperature and membrane thickness were varied. Permeation rate of these membranes were in the order of $-\mathrm{SO}_{3} \mathrm{H},-\mathrm{COONa},-\mathrm{SO}_{3} \mathrm{Na}$ and $-\mathrm{COOH}$ type. Permeation rate and separation factor of water to other gases exhibit high value. Permeation rate was not proportional to reciprocal of the membrane thickness such as typical gas separation membrane. Hollow fiber was fablicated by the fluorinated ion exchange polymer, and dehumidifier module was assembled. Dehumidification performance was measured by dew point meter. In the case of typical dehumidifier module (membrane area $0.02 \mathrm{~m}^{2}$, module length $22 \mathrm{~cm}$ ), dew point of dried air reached $-30^{\circ} \mathrm{C}$ when air flow rate was $20 \mathrm{~N} l / \mathrm{min}$. and purge air rate was $20 \%$. Membrane performance of the module was kept constant about 3 years at $40^{\circ} \mathrm{C}$.
\end{abstract}

Key words : dehumidifier module/hollow fiber/fluorinated ion exchange membrane/water vapor permeation

\section{1. 緒言}

除湿や加湿といった調湿操作はガス分離の中で も最も身近で重要なプロセスである.この調湿を 行うシステムとしては, 吸着法や冷凍法, 膜法が 挙げられるが, 中でも膜法は樹脂や液の再生が不 要であり, メンテナンスが容易, 装置が軽量でコ ンパクトで, 収納や移動が簡単, ダスト等を含ま
ないクリーンな空気が得られる, 現在問題となっ ているフロンを使用しない, などの特徵を持ち, 新しいシステムとして最近注目されている.

膜法による調湿の原理は, 通常のガス分離膜と 同様で, 膜の両側の水蒸気分圧差を駆動力として 水蒸気が膜内を透過するものである. 従ってこれ に用いられる素材としては, 水を取り込む力が強 くしかも低湿度においても透過性の高いもの, さ 


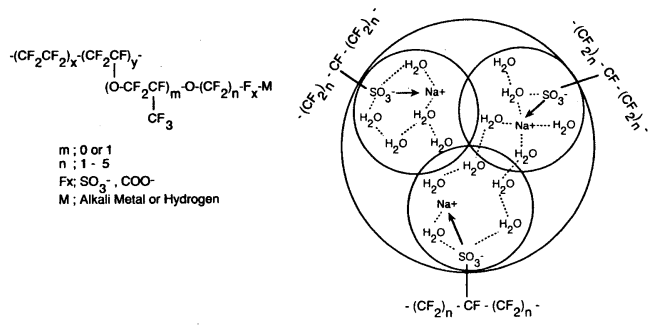

Fig. 1 Chemical structure and high-order structure of fluorinated ion exchange polymer.

Table 1 Water vapor permeability of fluorinated ion exchange membrane with different functional group.

\begin{tabular}{lcc}
\hline $\begin{array}{c}\text { Functional } \\
\text { group }\end{array}$ & $\begin{array}{c}\text { Membrane } \\
\text { thichness } \\
(\mu \mathrm{m})\end{array}$ & $\begin{array}{c}\text { Permeation } \\
\text { rate } \\
\left(\mathrm{cm}^{3} / \mathrm{cm}^{2} . \mathrm{s} . \mathrm{cmHg}\right)\end{array}$ \\
\hline$-\mathrm{SO}_{3} \mathrm{H}$ & 70 & $0.035 \sim 0.075$ \\
$-\mathrm{SO}_{3} \mathrm{Na}$ & 70 & $0.010 \sim 0.016$ \\
$-\mathrm{COOH}$ & 70 & $<0.005$ \\
$-\mathrm{COONa}$ & 70 & $0.003 \sim 0.021$ \\
\hline
\end{tabular}

らに水蒸気の選択透過性が高いものが必要であ る.このような素材の 1 つとして我々はフッ素系 イオン交換ポリマーに着目し, 高性能除湿膜モ ジュールを開発した（商品名サンセップ-W）．以 下にその結果を報告する。

\section{2. 各種フッ素系イオン交換ポリマーの 構造と水蒸気透過基礎特性}

フッ素系イオン交換ポリマーの 1 次構造および 高次構造を Fig. 1 に示す. フッ素系イオン交換 ポリマーはテトラフルオロエチレンとパーフルオ ロビニルエーテルの共重合体であり, ビニルエー テル側鎖の末端に親水性の官能基 $\left(-\mathrm{SO}_{3} \mathrm{H}\right.$ など） が結合している. 水の存在下では隣接する官能基 どうしが会合し, クラスター構造を形成する.

各種膜の水蒸気透過性能は, 平膜を用いて 1 次 側に水蒸気を満たし 2 次側に乾燥空気を流し得ら れる空気の湿度から算出するか，または 2 次側を 減圧にしてトラップし, トラップした水の重量か

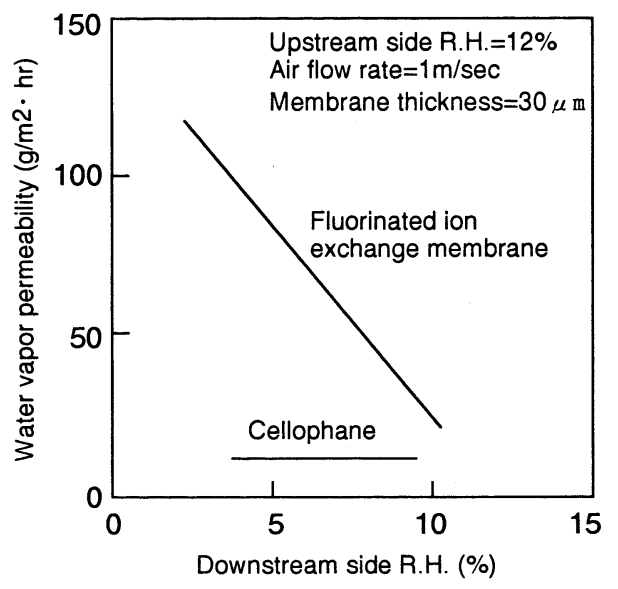

Fig. 2 Downstream side R. H. dependence of water vapor permeability of cellophane and fluorinated ion exchange membrane.

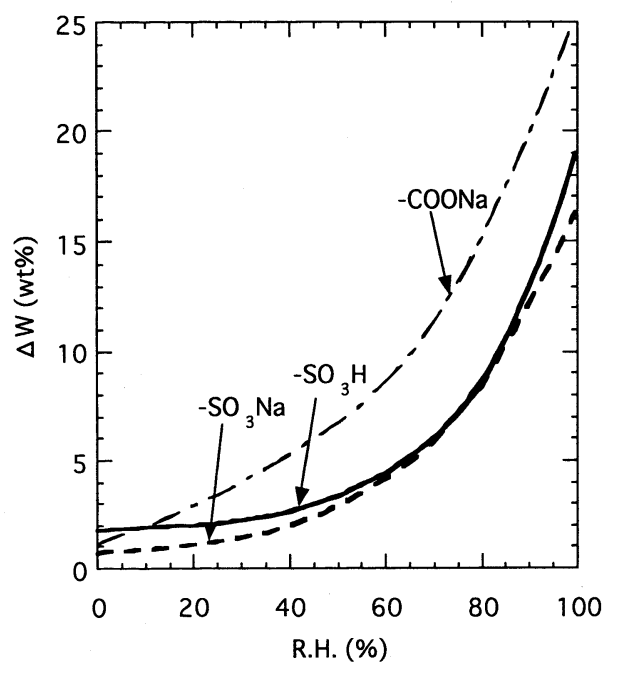

Fig. 3 Water content of fluorinated ion exchange membrane in different rerative humidity.

ら評価した.

Fig. 2 に代表的な炭化水素系親水性膜である セロハンとフッ素系イオン交換膜(スルホン酸型) の水蒸気透過量の乾燥側湿度依存性を示す. 乾燥 側湿度が比較的高い領域では両者とも大きな性能 の相違はないが，乾燥側湿度が低い領域ではフッ 


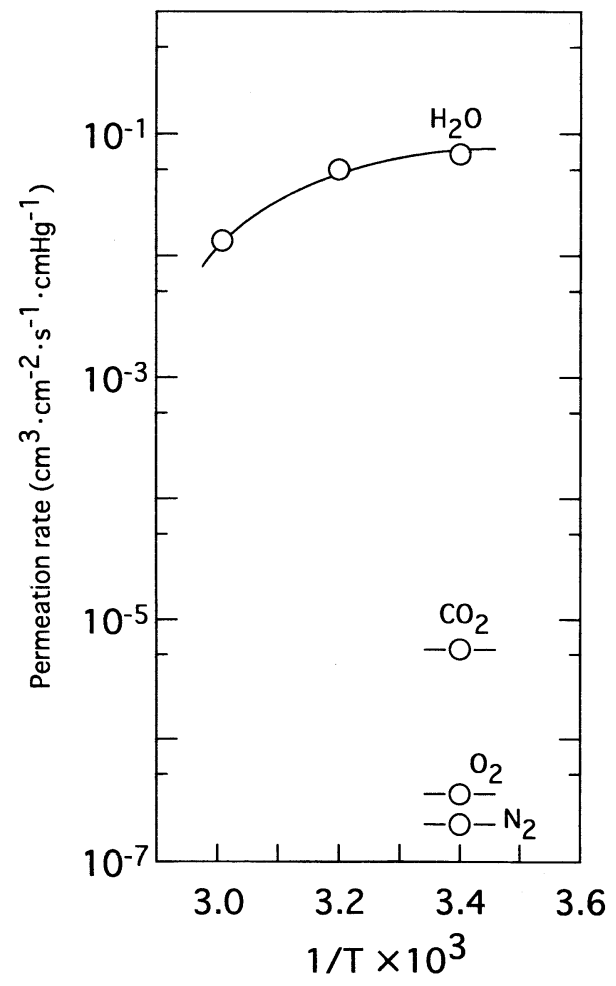

Fig. 4 Temperature dependence of water vapor permeation rate.

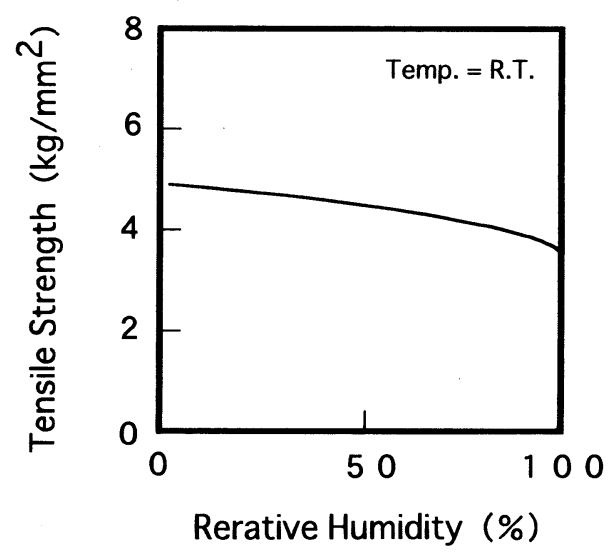

Fig. 6 R. H. dependence of tensile strength.

素系イオン交換膜はセロハンと比較して高い水蒸 気透過性を示し，フッ素系イオン交換膜が除湿膜 素材の要求特性として重要な, 水を取り込む力が 強く, しかも低湿度においても高い水蒸気透過性

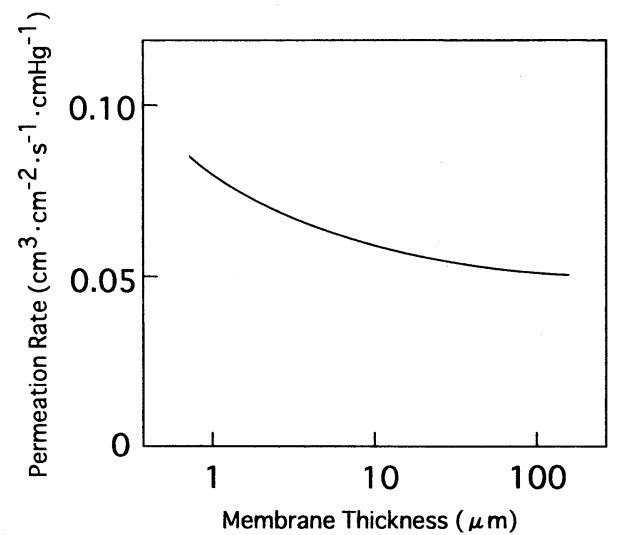

Fig. 5 Membrane thickness dependence of water vapor permeation rate.

を保持する特性を持っていることが明らかであ る.

そこで, フッ素系イオン交換膜に関して, 官能 基の種類と温度, 膜厚を変化させ水蒸気透過性能 を測定した. 結果を Table. 1 に示す. カルボン 酸型 $(-\mathrm{COOM})$ とスルホン酸型 $\left(-\mathrm{SO}_{3} \mathrm{M}\right)$ とを 比較すると, $-\mathrm{SO}_{3} \mathrm{H}$ 型が水蒸気透過性が最も高 く, 次に $-\mathrm{COONa}$ 型, $-\mathrm{SO}_{3} \mathrm{Na}$ 型, $-\mathrm{COOH}$ 型 の順となった.この理由を調べるために種々の湿 度における各膜の含水率を測定した. Fig. 3 にそ の結果を示す. 膜の 1 次側のように相対湿度の高 い領域では-COONa 型の含水率が高いが, 膜の 2 次側のように相対湿度の低い領域では $-\mathrm{SO}_{3} \mathrm{H}$ 型の含水率が高い. 親水性が高く膨潤する膜の透 過性の律速段階は抵抗の高い 2 次側と考えられ, 低湿度領域で高い含水率を持っ $-\mathrm{SO}_{3} \mathrm{H}$ 型膜の水 蒸気透過性が高くなるものと推測される. また $-\mathrm{SO}_{3} \mathrm{Na}$ 型の方が $-\mathrm{SO}_{3} \mathrm{H}$ 型より低湿度における 含水率が低く透過性が低くなるのは, 明確ではな いがイオン的な相互作用によるものと考えられ る. カルボン酸型の - $\mathrm{COOH}$ の場合, さらに含 水率は低く水蒸気透過性も低くなるものと考えら れる.

次に $-\mathrm{SO}_{3} \mathrm{H}$ 型膜の温度を変化させた場合の水 蒸気透過性を Fig. 4 に示す. 高温側では若干低 下がみられるが, 極めて高い透過速度を示した. また, 窒素, 酸素等に対して高い分離係数を示し 


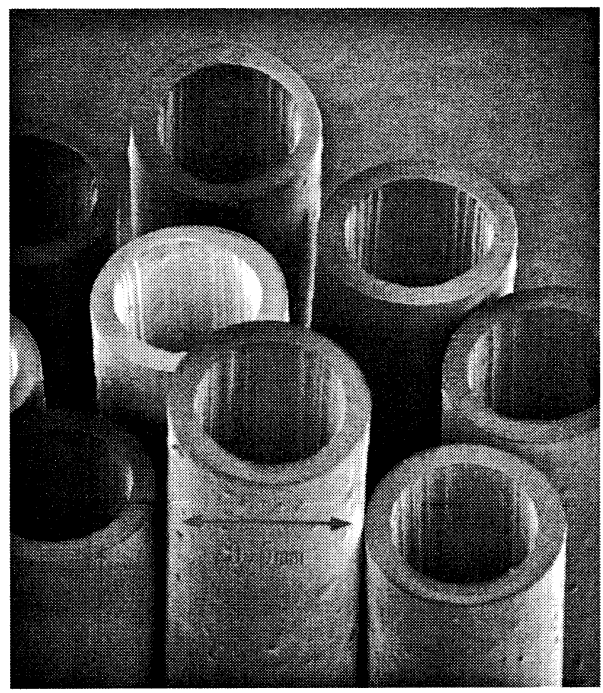

Fig. 7 SEM photograph of hollow fiber.

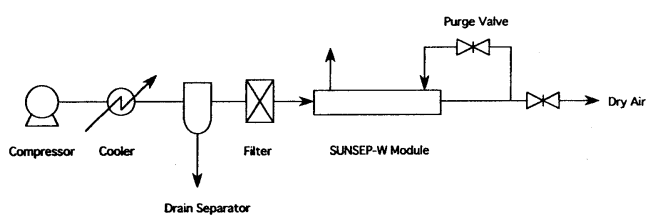

Fig. 9 Schematic representation of dehumidifier system.

ている.

Fig. 5 にこの膜の水蒸気透過性の膜厚依存性 を示す. 通常, ガス分離膜においては厚みに逆比 例して透過速度は増大するが，この膜の場合厚み の依存性は小さい. 水蒸気により膜が膨潤し, 膜 内部のある程度まで水が極めて早く移動している ことが予测される.

また, Fig. 6 にこの膜の引張り強度の相対湿度 依存性を示した．親水性ポリマーは乾燥状態では 高強度であっても含水状態では強度が極端に低下 するものがあるが, このポリマーは相対湿度 100\%でも比較的高い強度を示し, 強度低下は約 30\%にとどまった.

\section{3. モジュール構造と除湿性能}

次に, このフッ素系イオン交換ポリマーを用い

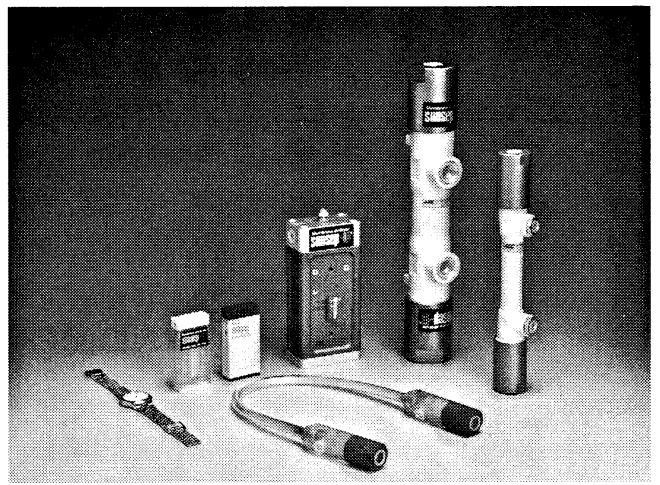

Fig. 8 Photograph of dehumidifier module.

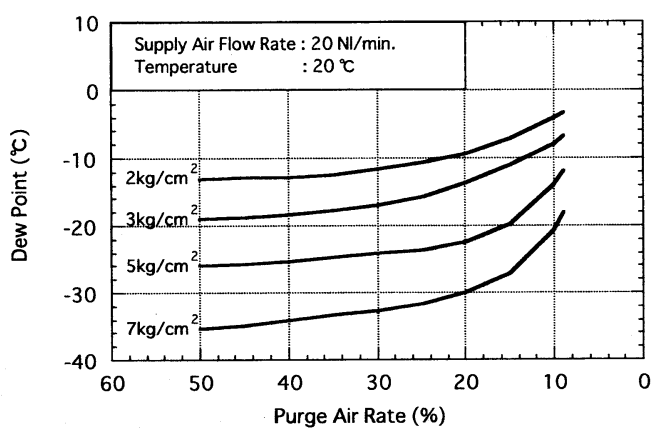

Fig. 10 Purge air rate dependence of dew point of module.

て中空糸膜を成形し，それらを束ねて両端をポッ ティング剂で固め, 中空糸膜モジュールを作成す ることとした. 中空糸の構造としては, 支持体を 用いる複層膜構造と単層膜構造とが考えられる. 複層膜では機能層を薄くできるというメリットが あるが, 拡散律速層ができること, 製造が容易で ないことなどのデメリットもある. 一方, 単層膜 の場合には製造は容易であるが, 機能層が強度保 持層を兼ねるため厚みが増大し, 一般的には透過 性が低下する欠点がある. しかしながらこの膜の 場合には, 前述のように水蒸気透過性の膜厚依存 性が低く, 膜厚が増大しても透過性があまり低下 しないため単層膜構造を採用することとした．中 空糸の外径は約 $550 \mu \mathrm{m}$ でフッ素系イオン交換ポ リマー単体からなる均質膜である. 中空糸の走査 型電子顕微鏡写真と代表的なモジュールの写真を Fig. 7 および 8 に示す. 

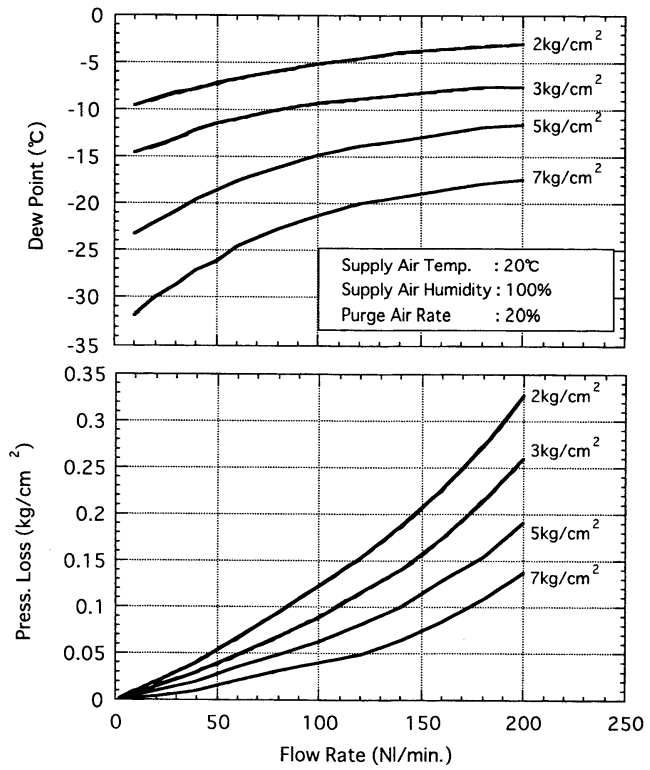

Fig. 11 Flow rate dependence of dew point and pressure loss.

得られたモジュールを用いた除湿装置の基本フ ローをFig. 9 に示す. 圧縮された空気はクー ラー, ドレン分離器, フィルターを通してモジュー ルに入り, 乾燥された製品空気の一部をパージし て除湿を行うために用いる. モジュールの除湿性 能は露点計を用いて測定した。モジュールの性能 は乾燥空気の到達露点, 空気利用率, 処理能力で 評価される. 代表的なモジュール（膜面積 : 0.02 $\mathrm{m}^{2}$, モジュール長 $22 \mathrm{~cm}$ ）の性能を Fig. 10, 11 に示す. 流量 $20 \mathrm{~N} l /$ 分の場合, $80 \%$ の空気利用率 でほぼ $-30^{\circ} \mathrm{C}$ の露点が得られる. $0.02 \mathrm{~m}^{2}$ と小 型であるにもかかわらず $-20^{\circ} \mathrm{C}$ の露点の乾燥空 気であれば $100 l /$ 分を越える流量で得られ, 処理 能力も大きいことがわかる. ポリマーが化学的に 安定であり, 膜構造も単純であることから，モ ジュールは優れた耐久性を示した. Fig. 12 に連

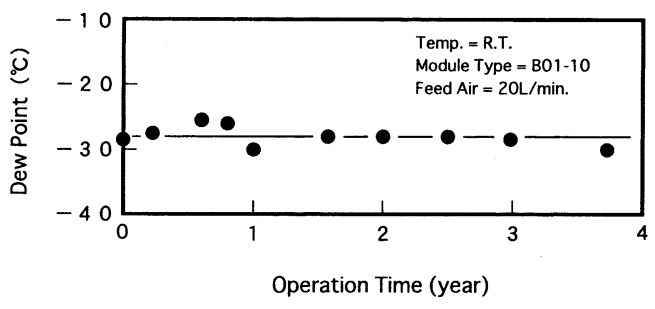

Fig. 12 Durability of dehumidifier module at room temperature.

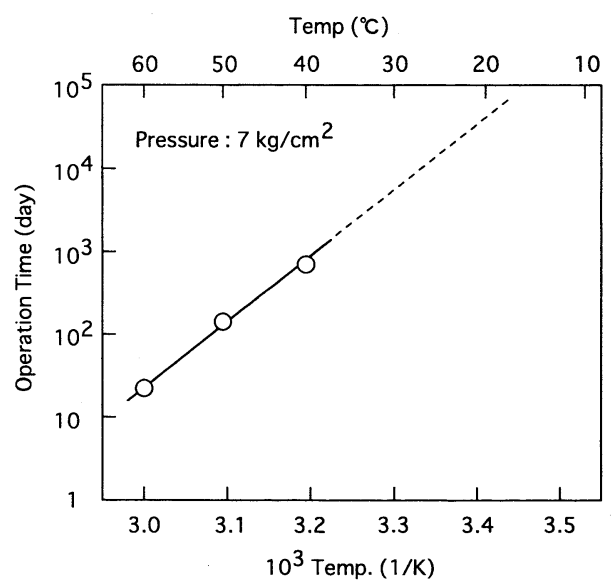

Fig. 13 Durability of dehumidifier module at different temperature.

続運転の結果を示す. 室温で約 4 年間にわたって 安定した性能を発現している.このモジュールの 耐久性の操作温度依存性を Fig. 13 に示す. $40^{\circ} \mathrm{C}$ においても約 3 年間安定した性能を発現してい る.

この除湿モジュールの応用例としては, 工作機 械（ロボット）用空気や分析機器用空気, 計装空 気等の脱湿や防爆エリアでの脱湿, 機器の腐食防 止, 医療機器への応用などが挙げられ現在一部の 用途で適用されつつあり, 今後の展開が期待され る.

（受付 1996 年 6 月 18 日 掲載決定 7 月 2 日） 